Vera Lúcia Salerno ${ }^{1}$

Mirian Pedrollo Silvestre ${ }^{1}$

Marcos Oliveira Sabino ${ }^{1}$

\section{Interfaces LER/Saúde Mental: a experiência de um Centro de Referência em Saúde do Trabalhador do Estado de São Paulo}

\author{
Repetitive Strain Injury and Mental Health: an experience of a Worker's \\ Health Reference Center in the state of São Paulo, Brazil.
}

\section{Resumo}

Este relato apresenta demandas que cada vez mais chegam aos Cerests desafiando as equipes multidisciplinares para o desenvolvimento de novas modalidades de abordagem diagnóstica e terapêutica. A experiência é de um Cerest do interior de São Paulo na última década. Construída a partir do relato de trabalhadores, visitas a locais de trabalho, discussão com representantes de empresas e atuação de equipe plurinstitucional de LER, ilustra situações de trabalho potencialmente adoecedoras, em especial do sistema musculoesquelético (LER/DORT). Trabalhadores de cinco empresas de quatro diferentes ramos relatam pressão para produção, sobrecarga física e competitividade, situações de humilhação ou constrangimento como forma de ajustá-los aos padrões da empresa, além da exposição pública e da "punição pelo adoecimento" dos acometidos pelos agravos que retornam ao trabalho. Verifica-se que há ainda grande deficiência no reconhecimento das situações em que o trabalho contribui para o adoecimento mental. Os profissionais da área da Saúde do Trabalhador devem estar especialmente atentos para identificar os casos de sofrimento mental nos portadores de LER/DORT e notificá-los. Recomenda-se que as informações geradas sejam reunidas, analisadas e divulgadas, de modo que possam ser instrumento para sensibilização dos profissionais de saúde em geral e gerar formas de intervenção mais eficazes à proteção à saúde dos trabalhadores.

Palavras-chave: LER/DORT; assédio moral; organização do trabalho; Centro de Referência em Saúde do Trabalhador (Cerest).

\begin{abstract}
This report presents some arriving demands at CEREST (Reference Center for Workers' Health) that have challenged its multidisciplinary team to develop new diagnostics and therapeutic approaches. The experience comes from a CEREST located in a inland city of the state of São Paulo, during the last decade, based on workers' reports, visits to work places, discussion with representatives of various sectors, as well as on the activity of the local Repetitive Strain Injury (RSI) pluri-institutional team. It illustrates work situations generating diseases and injuries in five companies, especially in the musculoskeletal system (RSI). Workers reported pressure to achieve production goals, physical overload and competition, humiliation and coercion as ways to fit them into company standards. Returning--to-work employees with RSI suffered public exposure and were "punished" for their illness. The report demonstrates that mental illness related to work is not adequately acknowledged yet. Professionals involved with Worker's Health must be especially alert to identify mental suffering in RSI carriers and notify it. The authors recommend that information should be gathered, analyzed and publicized to become a tool to create awareness among health professionals in general, and produce new and effective ways of intervention to protect workers' health.
\end{abstract}

Keywords: repetitive strain injuries; harassment; work organization; Occupational Health Center.
Revisado: 20/04/2011

Aprovado: 28/04/2011 


\section{Introdução}

O aparecimento de distúrbio mental e desordens neurovegetativas em trabalhadores submetidos ao processo de terceirização, à excessiva pressão no trabalho, ao prolongamento rotineiro das jornadas e sem qualquer adequação ergonômica tem sido bem discutido na literatura (BROUSSE et al., 2008; WANG, et al., 2008; ROMEO, 2007; MACEDO, 2007; CARLOTTO, PALAZZO, 2006; BRANT, DIAS, 2004; PALACIOS, DUARTE, CÂMARA, 2002). Há também relatos do aparecimento de transtornos físicos, inclusive mortes, gerados por estas transformações do mundo do trabalho (ALVES, 2009; MAGNAVITA, 2009; SUWAZONO, 2006; TOMEI, 2006; GLINA, 2001; SALERNO, 1998).

Nas ações realizadas pela equipe multidisciplinar do Centro de Referência em Saúde do Trabalhador de Campinas (Cerest), seja nos atendimentos individuais e grupais, seja nas fiscalizações em ambientes de trabalho, tem-se verificado este tipo de exploração em diversos ramos da atividade econômica.

As Lesões por Esforços Repetitivos/Distúrbios Osteomusculares Relacionados ao Trabalho (LER/DORT) constituem cerca de 85\% dos diagnósticos feitos nos atendimentos ambulatoriais do Cerest desde 1993. Boa parte destes pacientes tem também queixas e manifestações de ordem psíquica, diagnosticadas ou não como entidades nosológicas específicas, que por sua vez retroalimentam a dor, que, agravada, pode levar à piora do quadro psíquico. Forma-se, deste modo, um círculo vicioso perverso de dor e sofrimento mental que interfere negativamente na vida familiar, profissional e social do trabalhador. $\mathrm{Na}$ experiência do Cerest, o sofrimento mental manifesta-se de formas diferentes em cada pessoa. Para fins de simplificação de termos, estas manifestações serão denominadas, de forma genérica e reducionista, de quadros de ansiedade e quadros depressivos. O que existe de homogêneo nestes quadros de adoecimento é que suas causas são encontradas na inter-relação que se estabelece entre a vivência da dor crônica, causada pelas LER/DORT, e a insegurança em relação ao papel profissional, o medo do desemprego, a perda do status social. É importante notar também o desamparo experimentado pelo trabalhador no contato com os Serviços Especializados de Segurança e Medicina do Trabalho (SESMTs) e com a Previdência Social, estruturas destinadas, em princípio, a viabilizar direitos dos trabalhadores.

Este relato de experiência trata das relações entre sintomas mentais e LER/DORT encontradas nos atendimentos do Cerest, traduzidas pelos trabalhadores como "dor e humilhação". Busca entender as formas de coerção que atingem os trabalhadores, na forma definida por Leymann (1990): a má gestão dos conflitos está relacionada à má organização do trabalho. E, por meio deste entendimento, busca identificar as formas de atuação das equipes de saúde do SUS junto aos trabalhadores e empregadores na garantia à saúde.

\section{Metodologia}

Foram estudadas cinco empresas, nas quais foram identificadas situações potencialmente adoecedoras, em especial do sistema musculoesquelético, incluindo esforços, realização de movimentos repetitivos em ciclos de trabalho curtos, posturas de trabalho viciosas e ritmo intenso de trabalho. A identificação de tais riscos ocorreu a partir de informações colhidas em atendimentos individuais a trabalhadores, atendimentos coletivos, vistorias aos locais de trabalho e discussões com representantes das empresas - prepostos, representantes jurídicos e/ou gerentes de recursos humanos.

Todas as abordagens descritas foram realizadas por equipe multidisciplinar do Cerest. As vistorias em ambientes de trabalho foram realizadas entre 1997 e 2009, sempre com a presença do sindicato de trabalhadores da categoria, seguindo rotina da Vigilância em Saúde no Cerest.

Considerou-se a pesquisa qualitativa como a mais indicada para o que se quer estudar neste relato de experiência, por permitir a compreensão de uma ampla gama de significados, particularmente nas situações em que relações, processos e fenômenos não podem ser adequadamente mostrados por meios numéricos ou estatísticos, ou seja, não podem ser reduzidos à operacionalização de variáveis (MINAYO, 1994).

Em duas das empresas estudadas foram realizadas atividades em grupos, descritas como enquetes coletivas por Rigotto (1994), nas quais os trabalhadores discutiram em ambiente protegido, ou seja, fora do local de trabalho, suas impressões do processo de trabalho e fizeram críticas ao que foi observado nas vistorias feitas pelos técnicos do Cerest. A análise do material foi feita buscando unir o conhecimento teórico ao que se viu e viveu na prática, levando em conta que os autores são parte do processo investigativo e que o conhecimento obtido por meio deste estudo mostra uma fração da realidade. O processo de análise foi semelhante ao proposto por Rockwell (1986), escolhendo no contexto aquilo que parece demonstrar de forma mais adequada o objetivo que se pretende alcançar. As hipóteses são criadas e recriadas a partir das interpretações que vão sendo feitas.

\section{Resultados}

\section{Empresa 1}

Lavanderia com 60 trabalhadores, maioria formada por mulheres casadas, moradoras nas imediações da empresa. Atende a hotéis, hospitais e restaurantes, de modo que tem movimento contínuo, que aumenta nos feriados e períodos de festas. Opera em dois turnos (das $6 \mathrm{~h}$ às $14 \mathrm{~h}$ e das $14 \mathrm{~h}$ às $22 \mathrm{~h}$ ). Os empregados da empresa relataram, nos atendimentos individuais e nos grupos de tratamento feitos por equipe multidisci- 
plinar, que quase diariamente os trabalhadores do primeiro turno estendiam a jornada por uma a duas horas extras, havendo intervalo de 20 a 30 minutos para almoço. Relataram também que os trabalhadores que entravam às $14 \mathrm{~h}$ frequentemente permaneciam até a meia noite ou uma hora da manhã, horário no qual chegava a condução que os levava para casa. Esta era a única alternativa para sair da empresa depois das $22 \mathrm{~h}$, visto que o bairro onde fica a lavanderia é conhecido no município pelo tráfico de drogas e pela violência. Vinte por cento dos empregados da empresa tinham doenças reconhecidas pelo Cerest como LER/DORT, alguns notificados por Comunicação de Acidente de Trabalho (CAT) e todos registrados no banco de dados dos atendimentos ambulatoriais realizados no Cerest, conhecido como SIAMAP $2 \mathrm{~K}^{2}$.

Todos os pacientes atendidos com diagnóstico de LER/DORT relataram situações - anteriores ao adoecimento e que persistiam até o momento das entrevistas - de cobrança por produtividade, ausência de rodízios, obrigação de fazer horas extras e de trabalhar nos domingos e feriados, havendo relato de advertência dada a uma trabalhadora que se recusou a fazer hora extra durante o Natal. Nas vistorias feitas pela equipe do Cerest foram verificadas condições ergonômicas inadequadas, com bancadas excessivamente altas, máquinas de lavar e secar antigas, calandras defeituosas, ferros de passar roupa pesados, manipulação de lençóis, toalhas e aventais volumosos e em grande quantidade, confirmando situações apontadas pelos trabalhadores durante os atendimentos no Cerest. Os relatos de pressão no trabalho não puderam ser constatados in loco, aparecendo somente nos atendimentos individuais e em grupo. No entanto, os relatos foram feitos de forma tão precisa, coerente e específica, que permitiram que fosse identificada a abordagem agressiva por parte da empresa por meio de constrangimentos impostos a trabalhadores de forma coletiva.

Existe, pelo que contam os trabalhadores, grande solidariedade entre eles no local de trabalho. As tarefas são divididas de forma genérica (separação de roupas, lavagem, dobra, calandra ou ferro de passar), mas um trabalhador ajuda o outro quando repara que há sobrecarga de tarefas. Isto é esperado por parte do encarregado e, ao mesmo tempo, explorado. Nos dias em que há sobrecarga de trabalho, o que é muito frequente, é mais rara a ajuda entre colegas. $\mathrm{O}$ trabalhador que não dá conta de sua tarefa e não ajuda o colega é chamado no escritório e repreendido por não colaborar. Daí, no próximo período em que houver sobrecarga, este trabalhador irá se esforçar para dar conta da sua tarefa e poder ajudar outro colega sobrecarregado. Caso tenha dificuldade em ajudar os colegas por repetidas vezes, começa a ser criticado em voz alta pelo encarregado, no espaço de trabalho, críticas que muitas vezes são repetidas por alguns colegas (em geral, novatos). O contro- le, portanto, é exercido pelo encarregado, que utiliza os colegas de trabalho como instrumento de coerção. Um caso exemplar desta forma de discriminação é o de uma trabalhadora que teve diagnóstico de LER/DORT grave estabelecido em 2004, quando foi afastada do trabalho para tratamento, sem sinais de transtornos mentais. Após o terceiro retorno ao trabalho, sem qualquer processo de reabilitação, demonstrava sofrimento mental, que foi diagnosticado como depressão e síndrome do pânico pelo psiquiatra que passou a acompanhá-la na unidade de atenção primária à saúde. Esse agravamento clínico, bem com as recomendações da equipe do Cerest não a protegeram de uma advertência por escrito da empresa, motivada por não poder realizar horas extras.

\section{Empresa 2}

Empresa que centraliza atendimento telefônico para fornecer informações, receber queixas, vender produtos. Trata-se de empresa terceirizada que vende serviços para empresa de telecomunicações. Opera em regime de 24 horas e tem cerca de 1.200 empregados que trabalham em turnos fixos de quatro ou seis horas. Nos casos de turno de seis horas, estão previstos quinze minutos para lanche e uso de banheiro. Há dois locais para refeições: um no décimo andar e outro no subsolo, junto da garagem, cujos acessos são feitos por escada ou elevador. Nos horários de refeições, que coincidem com entrada e saída das turmas, há congestionamento nos elevadores, de modo que o percurso até os locais de refeições pode levar até dez minutos entre ida e volta. Cada operador tem um tempo médio de operação (TMO) que varia de acordo com a tarefa desempenhada: de vinte segundos (para informações sobre telefones) a quatro minutos (para vendas de produtos e recebimento de reclamações).

Há complexidade no trabalho, semelhante à descrita por Ferreira Jr. (1997) e Silva (2007), que inclui, ao mesmo tempo, operação de computador, telefone e contato rigidamente controlado com os usuários do serviço. Além disso, os empregados sabem que frequentemente têm seus atendimentos ouvidos por supervisores, que verificam a qualidade do atendimento, o seguimento da fraseologia, a efetividade na resolução das reclamações.

Nesta empresa não houve dificuldade para a fiscalização demonstrar a existência de pressões por produtividade e estímulo à competição. A forma como a empresa organiza a produção inclui a competição entre empregados e a cobrança de cada um perante os colegas, o que é estimulado por meio de listas que mostram os trabalhadores mais rápidos, que ganharão prêmios para sua equipe, e os trabalhadores mais lentos, responsáveis pela perda de pontos para a equipe à qual pertencem. Tais listas ficam afixadas nos corredores e são visíveis por qualquer pessoa, tendo sido inclusive fotografadas pela fiscalização do Cerest. Durante a fiscalização, constatou-se a existência de

2 SIAMAP 2K: base de dados ambulatoriais em EPI-INFO/DOS, feita em 2000 e atualizada diariamente, disponível no Cerest Campinas. 
um painel digital em cada sala que mostrava, a todo momento, o número de chamadas que estavam sendo feitas pelos usuários do serviço e não atendidas. Ao mesmo tempo indicava qual era o número máximo de chamadas não atendidas toleradas pela empresa contratante, número esse que, se ultrapassado, resultaria em quebra de contrato e demissão de todos os empregados da empresa de teleoperação.

Como agravantes, vale ressaltar dois aspectos. Um deles é que a empresa em nenhum momento aceitou o fato de ser responsável por oferecer risco à saúde dos seus empregados, e por este motivo sempre se recusou a introduzir pausas para descanso ou aumentar o TMO. Outro agravante se refere à participação do sindicato. A equipe do Cerest observou que em nenhum momento, apesar de insistentes convites, houve comparecimento dos diretores sindicais às reuniões feitas com os trabalhadores. Por outro lado, estes diretores compareceram a todas as reuniões feitas com prepostos, gerentes e advogados da empresa vistoriada, sempre em postura de defesa da empresa.

Constatou-se que, nas vistorias das quais o sindicato havia participado, não foram flagradas as situações relatadas pelos trabalhadores em consultório quanto à existência de práticas constrangedoras, tais como avisos e listas supramencionadas com nomes de trabalhadores. Isso mesmo apesar de as vistorias serem feitas, por princípio, sem prévio aviso às empresas. Entretanto, a partir da decisão da equipe técnica do Cerest de não avisar o sindicato da categoria com antecedência, deixando para avisá-los e convidá-los imediatamente antes da saída a campo, foram constatados avisos e cobranças por produção. Nos sucessivos atendimentos individuais com os trabalhadores, foi unânime a afirmação de que o sindicato não tinha postura atuante pró-trabalhador, nem era considerado confiável.

Informações obtidas a partir de levantamento de prontuários no Cerest mostram que entre 2000 e 2009 foram atendidos 65 trabalhadores da empresa, com confirmação de 59 casos de LER/DORT. Em 46 casos houve solicitação ou emissão de CAT. Nos outros 13 casos, as CATs não foram emitidas, fosse por falta de interesse por parte do paciente, ou porque havia sido demitido da empresa, e neste caso a CAT poderia dificultar a obtenção de outro emprego, ou por medo de que a CAT pudesse gerar represálias no trabalho, preocupação que posteriormente se revelou justificada.

No início do processo de intervenção, a empresa emitiu CAT conforme solicitado pelo Cerest. Com o aumento no número de diagnósticos, por orientação de seu próprio departamento jurídico, conforme consta de Inquérito Civil Público no Ministério Público do Trabalho, a empresa deixou de notificar os casos ao Instituto Nacional do Seguro Social (INSS), mesmo quando o procedimento foi requisitado por meio de ação de Vigilância Sanitária. Dessa forma, vários dos casos diagnosticados no Cerest foram encaminhados pela empresa ao INSS com solicitação para concessão de auxílio doença comum. Em alguns casos, o benefício previdenciário foi transformado em auxílio doença acidentário, mas vários deles não obtiveram o reconhecimento do nexo causal por parte da perícia do INSS.

Uma das hipóteses para o não reconhecimento do nexo causal por parte da perícia do INSS direciona-se para o fato das notificações terem sido feitas por CATs não emitidas pela empresa, pois alguns trabalhadores afirmaram que receberam essa informação verbalmente na Previdência Social. De fato, isso não condiz com a legislação previdenciária, mas em nossa demanda temos observado que doenças ocupacionais notificadas com CATs emitidas por empresas têm, via de regra, o nexo causal imediatamente reconhecido, o que ocorre com menor frequência com as CATs emitidas por sindicatos, serviços de saúde ou pelo próprio trabalhador.

A partir disso, novos relatos compatíveis com violência psicológica foram trazidos em atendimentos individuais, demonstrando o propósito da empresa em conter os casos notificados. Duas trabalhadoras com diagnóstico de LER/DORT pediram em consulta que seus casos não fossem notificados à empresa em função das perseguições ocorridas contra colegas que haviam se afastado. Uma trabalhadora foi demitida ao apresentar solicitação de CAT feita pelo Cerest.

\section{Empresa 3}

Empresa de eletroeletrônicos que empregava cerca de 700 pessoas, maioria mulheres, que trabalhavam com movimentos repetitivos e esforços principalmente de mãos e dedos. Entre 93 trabalhadores avaliados, foram diagnosticados, no Cerest, 51 casos de LER/DORT no período de 1991 até 2004, quando a empresa transferiu-se para outro estado. Os diagnósticos mais frequentes foram Síndrome do Túnel do Carpo e Tendinite de De Quervain. Os trabalhadores foram afastados do trabalho para tratamento e houve muita dificuldade na reabilitação profissional pelo fato de a empresa não concordar com os diagnósticos de doença ocupacional e declarar não ter interesse no retorno ao trabalho daquelas pessoas. As declarações por parte dos prepostos da empresa eram feitas diretamente de forma literal, verbal, aos profissionais das equipes de atendimento e às autoridades sanitárias que atuavam junto à empresa. O contato era feito por telefone ou pessoalmente (durante as vistorias e as discussões de casos individuais sobre restrições no trabalho) e algumas vezes escritas pelo diretor de Recursos Humanos, negando o adoecimento, a relação com o trabalho e manifestando desinteresse na manutenção de determinado trabalhador nos seus quadros de empregados. Tal situação levou vários trabalhadores a moverem processos trabalhistas contra a empresa, alguns dos quais ainda em curso. Houve exaustivas tentativas de readaptação feitas por equipe plurinstitucional, o Grupo Interinstitucional de LER (GIL), que incluía o Ministério Público do Trabalho, o Ministério do Trabalho e Emprego, a Perícia Médica do INSS, o Centro de Reabilitação Profissional do INSS, o Cerest, os sindicatos dos trabalhadores de algumas categorias e uma universidade 
local, a Pontifícia Universidade Católica de Campinas. Finalmente, a empresa fez um acordo com o GIL segundo o qual estes trabalhadores teriam como local de trabalho uma sala, separada do processo de produção, onde fariam atividades que a empresa determinaria periodicamente.

Assim, a partir de 1999, os trabalhadores acometidos por LER/DORT passaram a ser colocados em uma sala, onde cumpriam jornada de oito horas, sem atribuição de atividade fixa, mas com eventuais demandas por tarefas em "atividades compatíveis" com a capacidade física de cada um.

Em poucas semanas, as trabalhadoras "reabilitadas", alocadas na tal sala, voltaram a procurar o Cerest em atendimentos individuais com relatos sistemáticos sobre as condições reais de trabalho a que estariam submetidas. Referiram que ficavam confinadas em sala fechada, com janela estreita localizada a dois metros de altura. Referiam que haviam recebido orientação dos gerentes da empresa de que deveriam permanecer sentadas em cadeiras em torno de uma mesa, estando proibidas de realizar quaisquer atividades que não fossem determinadas pela empresa, tais como ler, fazer trabalhos manuais, conversar, fazer alongamentos, sair da sala para andar ou mesmo limpar a sala que, segundo relatos, era bastante empoeirada. Somado a isso, havia muito pouca ou quase nenhuma atividade de trabalho demandada pela empresa, o que acabou resultando em confinamento durante toda a jornada de trabalho, sem possibilidade de realizar qualquer coisa útil, fosse para a empresa, fosse para elas próprias. Foi feita vistoria por equipe do Cerest e os relatos foram constatados. Foram feitas propostas para a empresa (pelo Cerest, pelo sindicato da categoria) no sentido de estabelecer tarefas adequadas às pacientes. Não houve acordo. A tal sala ficou conhecida entre as trabalhadoras como "salinha" e era entendida por elas como forma de pressão exercida pela empresa para que pedissem demissão, uma vez que tinham estabilidade no trabalho por força de acordo coletivo firmado com o sindicato.

Todos os trabalhadores confinados na "salinha" desenvolveram distúrbios psíquicos. Para 10 deles o Cerest emitiu CAT por estresse ocupacional, uma vez que ficaram caracterizadas reações ao estresse grave e transtornos de adaptação. Outros 20 trabalhadores que estiveram confinados na "salinha" tiveram diagnósticos de depressão de gravidade variável, que também foram relacionados ao trabalho, mas não quiseram que fossem emitidas as respectivas CAT. Manifestavam apenas o desejo de se verem livres da empresa.

A estratégia de constrangimento utilizada pela empresa teve impacto sobre os trabalhadores, pois, a partir de 1999, o Cerest atendeu a muitos outros trabalhadores com queixas de dor musculoesquelética que pediam sigilo sobre seu atendimento por medo de que os gerentes da empresa soubessem de sua ida ao serviço de saúde. Eles não aceitavam atestados para afastamento do trabalho nem queriam CAT. Vinham apenas em busca de algum remédio que os ajudasse a continuar trabalhando.

\section{Empresas 4 e 5}

Duas empresas privadas que terceirizam o serviço de merenda escolar para o município de Campinas:

O Programa Municipal de Alimentação Escolar de Campinas atende 407 escolas (municipais e estaduais), além de 39 entidades assistenciais conveniadas com a Prefeitura e 121 salas de aulas de educação de jovens e adultos, um total de 159.514 alunos. A merenda escolar é administrada pela Secretaria Municipal de Educação em parceria com a Ceasa-Campinas. (FERNANDES, 2010, p. 1)

Todo este trabalho é feito por pouco mais de 600 trabalhadores, sendo uma parcela mínima de funcionários da própria Prefeitura e a maioria de trabalhadores de duas empresas terceirizadas.

Desde meados de 2004, o Cerest tem recebido trabalhadores que atuam no preparo e na distribuição da merenda escolar, encaminhados pela rede básica de saúde por suspeita de doenças ocupacionais. Cerca de 50\% dos casos atendidos tiveram diagnóstico de LER/DORT.

Os relatos dos pacientes foram de situações de sobrecarga de trabalho, instalações deficientes da cozinha nas escolas, violência em algumas escolas, particularmente atingindo a pessoa responsável pela distribuição de alimentos, a merendeira. Contaram que, de um lado, as pessoas que os pacientes chamam de "bandidos" exigem comida. De outro lado, existe a pressão de não poderem fornecer alimentação a quem não for aluno da escola. Os trabalhadores eram levados a crer, a partir de explicações feitas por seus empregadores, que estes problemas seriam exclusivos de cada um deles, gerados em função de seu comportamento, da firmeza com que tratassem alunos e não alunos. Relatavam que eram orientados pelo empregador a resolver sozinhos estes problemas ou a pedir demissão.

As fiscalizações realizadas pelo Cerest e os relatórios de vistorias feitos por setores de nutrição e fiscalização de alimentos evidenciaram presença de má organização do trabalho, instalações físicas pequenas, estreitas, algumas vezes com torneira escoando em ralos ao invés de pias ou tanques, de mobiliário antigo e malconservado, bancadas de trabalho muito altas ou muito baixas, panelas pesadas, ausência de mecanização do trabalho, obrigando a que todo o trabalho de preparo dos alimentos fosse feito manualmente. Chão escorregadio, locais pequenos e apertados.

Constatou-se também demanda excessiva de refeições/merendas em relação ao número de trabalhadores alocados em cada escola, como, por exemplo, numa escola onde um merendeiro deveria preparar e servir refeições completas para adultos jovens a partir de cardápio predeterminado pelo setor de nutrição e arrumar a cozinha para uma demanda de 800 alunos em um único período do dia. Apesar de não termos encontrado qualquer estudo na literatura que faça referência a um número adequado de merendeiras por aluno, pudemos observar que o trabalho exigido para 
que 800 refeições fossem preparadas e servidas até o horário do almoço excedia em muito a capacidade de uma única pessoa, dados a complexidade e o volume de tarefas. E mais, durante o processo de intervenção, constatamos que o critério para contratação da empresa terceirizada é puramente financeiro, realizado por pregão, de acordo com o Decreto Estadual nº 47.297 (SÃO PAULO, 2002), entre outros, não havendo qualquer alusão ao número de trabalhadores que deverá ser alocado em cada escola ou creche.

Após vistorias em oito cozinhas de escolas e creches, atendimentos realizados aos trabalhadores, discussões com a empresa terceirizada e com a tomadora de serviço, a equipe do Cerest constatou a ocorrência de sobrecarga constante das merendeiras, que trabalham sempre no limite máximo de suas possibilidades. No caso de ausência não prevista de um trabalhador e, pelo averiguado, algumas vezes ausência prevista com antecedência, como em caso de cirurgias eletivas ou licença maternidade, deveria ser enviada à escola uma merendeira "volante". Segundo as empresas contratadas para terceirizar o serviço de merenda escolar, a indicação do "volante" é feita entre os empregados mais recentes ou os que retornam de afastamento para tratamento de saúde, seja por doença relacionada ao trabalho ou não. $\mathrm{O}$ esquema de substituição nem sempre funciona, de modo que se constatou em fiscalização um flagrante em que o previsto seria a presença de quatro merendeiras, mas na realidade havia apenas uma, pois as outras três estariam afastadas por doença, por licença maternidade e demissão recente. Na prática, a partir dos relatos de trabalhadoras, fica claro que "volante" é um posto não desejado e ser colocada como volante é uma forma de ser castigada.

Como é previsto por lei, ao ser feito um diagnóstico de doença do trabalho, é solicitado ao empregador que emita CAT. O principal objetivo da emissão de CAT, além de garantir os direitos previdenciários dos trabalhadores, é permitir que sejam desenvolvidas ações de identificação de risco e promover ações de proteção à saúde. Nos primeiros casos de LER/DORT identificados, as empresas cumpriram com sua obrigação. Quando a demanda das merendeiras começou a tomar vulto, em 2004, as empresas passaram a negar a emissão de CAT. Diante da negativa sistemática na emissão das CATs e do aumento no número de trabalhadores da merenda escolar atendidos pelo SUS com diagnóstico de doença ocupacional, foi tomada a iniciativa de se promover reuniões com os dois principais empregadoras destes trabalhadores. Estas reuniões foram feitas conjuntamente pelo Cerest, pelo órgão regional do Ministério do Trabalho e Emprego, a Gerência Regional de Campinas e por representantes da Prefeitura, na qualidade de contratante. Uma das informações que se destacou nestas reuniões foi que o contrato entre o município e as empresas terceirizadas é feito por pregão, que privilegia a empresa que oferecer o produto solicitado pelo menor preço, sem levar em conta que o "objeto" de compra é o serviço humano. Os critérios do tipo e do número de refeições servidas por escola não é levado em conta no pregão. Tanto as contratadas, quanto os contratantes (os gerentes do Programa Municipal de Merenda Escolar) não souberam explicitar o critério de decisão do número de trabalhadores a ser contratado, nem o número previsto de merendeiras em relação ao número de alunos ou qualquer outro critério.

A partir da negativa das empresas em cumprir com sua obrigação, as CATs passaram a ser emitidas pelas autoridades sanitárias do SUS e foi instaurado processo administrativo contra as empresas. No entanto, estas CATs foram sistematicamente desconsideradas pela perícia médica do INSS, da mesma forma exposta na Empresa 2. Houve também cessação de benefício de forma indevida, antes do quadro de LER/DORT estar estabilizado, e ausência de encaminhamentos para reabilitação profissional.

Desta forma, os trabalhadores passaram a ter prejuízo também na esfera trabalhista e previdenciária, uma vez que, não tendo o reconhecimento legal da doença relacionada ao trabalho, deixaram de ter estabilidade de um ano no trabalho a partir da cessação do benefício. Por isso, no retorno ao trabalho após afastamento por doença, prestaram-se a qualquer tipo de tarefa pelo medo da demissão.

A alternativa ainda hoje oferecida aos trabalhadores quando retornam após afastamento para tratamento de doença, inclusive LER/DORT, é atuar como "volantes”, como já comentado. Isto significa que eles ficam à disposição da empresa para serem enviados cada dia à escola que precisar de reposição de merendeira. Não têm, portanto, local de trabalho fixo, podendo ser enviados para escolas com maior ou menor demanda de trabalho, sem que tenham qualquer controle sobre isso. A localização das escolas para as quais são enviados independe do seu local de moradia.

Estas situações contribuem para piorar o quadro de doença osteomuscular. Com frequência geram também sofrimento mental, expressos pelos pacientes como insegurança pela dor crônica, pelo não reconhecimento de sua situação, pelo medo da demissão e pela dificuldade em cumprir com as tarefas demandadas pela empresa. Esta dificuldade no desempenho de tarefas gera lentidão e piora a qualidade final do trabalho. É mal vista por colegas, pela direção das escolas e, obviamente, pela empresa contratante. A maioria dos trabalhadores da merenda escolar atendidos manifesta tristeza por não poder mais oferecer alimentos "bons" às crianças e aos alunos. Sentem-se desqualificados em sua competência profissional, gerando maior sofrimento. O esquema de trabalho como volante traz ainda mais insegurança. O trabalhador encontra um colega diferente a cada dia de trabalho, e, sem o convívio diário, vive a incerteza de encontrar apoio neste colega. Pela mesma razão, é prejudicado o estabelecimento de relações solidárias entre os próprios trabalhadores.

Foram revisados 27 prontuários de trabalhadores/ merendeiras contratados pelas empresas terceirizadas, atendidos no Cerest entre 2002 e 2009. Em 15 ca- 
sos (55,5\%) foi confirmado diagnóstico de LER/DORT, sendo que em 6 deles houve queixas relacionadas à saúde mental, tais como ansiedade e depressão.

\section{Discussão}

Na primeira empresa, ressaltam-se o componente da sobrecarga física importante e a solidariedade entre as trabalhadoras, nos "velhos moldes". Na segunda situação, o ritmo, a produtividade, a competitividade, a exposição pública humilhante e a violência psicológica. Na terceira situação, as dificuldades de reabilitação profissional em uma empresa eletroeletrônica e a existência de exposição pública por meio da "salinha". Na quarta situação, o agravamento pelo fato da terceirização e a "punição" pelo adoecimento - "volantes".

As descrições acima de relação entre sintomas mentais e LER/DORT encontradas nos atendimentos do Cerest, formando um círculo vicioso perverso, traduzidas pelos trabalhadores como "dor e humilhação", estão descritas na literatura especializada. Scopel (2005) avaliou as dificuldades no retorno ao trabalho de metalúrgicos afastados por LER/DORT e concluiu que o contexto encontrado está de acordo com as descrições da literatura: há um papel importante na valorização positiva do ato de trabalhar e na busca de atendimento precoce, de modo a evitar afastamento do trabalho e punições que possam decorrer consequentemente.

Um estudo publicado pela Organização Mundial da Saúde (2003) identificou os seguintes fatores como facilitadores para retorno ao trabalho: a troca de função, o controle do trabalho pelo trabalhador e o apoio dos colegas e supervisores. O mesmo estudo apontou, entre os fatores dificultadores, a alta prematura (correspondente, entre nós, à cessação de benefício do INSS), o retorno na mesma função, a ausência de programas de retorno, a dificuldade no relacionamento com supervisores e colegas, as dificuldades para impor limites às tarefas, o medo de demissão, os sentimentos de impotência e a insegurança quanto ao futuro. $\mathrm{O}$ estudo constatou ainda que os trabalhadores preferem se manter no trabalho.

Numa investigação das relações entre o conteúdo do trabalho e a ocorrência de distúrbios psíquicos menores $\left(\mathrm{DPM}^{3}\right)$, Reis et al. (2005) encontraram associação positiva com demanda psicológica e associação negativa com controle sobre o trabalho, constatando que quanto maior foi a exigência de atenção no trabalho e a autocobrança para não errar (alta demanda - baixo controle), tanto maior foi o número de ocorrências de DPM. Por outro lado, quanto maior foi o controle dos trabalhadores sobre as atividades e as tarefas, menor foi o número de doenças encontrado. Essa investigação corresponde ao clássico modelo demanda/controle de estresse - modelo que foi desenvolvido por Karasek (1985) no final dos anos 1970.

Ao fazer o levantamento dos prontuários de pacientes atendidos no Cerest para este relato, constatou-se que, embora estejam anotados relatos de experiência de pacientes sobre serem pressionados e até assediados no trabalho, não havia, na maioria dos casos, o diagnóstico específico de transtorno mental. Nas anotações de prontuário, há queixas de tristeza, crises de choro, medo de retornar ao trabalho, insegurança em relação ao trabalho, insegurança e conflitos na relação familiar desencadeados a partir da incapacidade para o trabalho. Há prescrição de medicamentos antidepressivos, encaminhamentos para psicoterapia individual e atividades em grupo que incluem discussões sobre processo de trabalho e sessões de relaxamento. Porém, as palavras Depressão, ou Ansiedade, ou outra que indique algum grau de sofrimento mental diagnosticado ou em investigação, não aparecem entre os diagnósticos. As razões desta negação de diagnóstico não são objeto deste estudo.

Na Empresa 1, o principal aspecto é a sobrecarga de trabalho sem avaliação individual, o que permite solidariedade e coleguismo. O fato de haver "apenas" um registro de diagnóstico de depressão pode estar relacionado à explicação acima. Observou-se nesta empresa uma grande coesão entre as trabalhadoras, que se conhecem do bairro, da escola dos filhos, muitas são vizinhas. Pelos relatos colhidos no Cerest e pelo que foi observado nas vistorias, os trabalhadores da empresa, na maioria mulheres, não têm comportamento competitivo e colaboram entre si na execução das tarefas. As pacientes chamam-se umas às outras de "meninas" e não há relato de discriminação entre as enfermas e as (ainda) saudáveis. Isto poderia estar servindo de apoio para minimizar o sofrimento causado pela excessiva pressão por produção. O INSS reluta em fazer uma real readaptação profissional - conforme previsto no Regime Geral da Previdência, Lei Federal nº 8.213 (BRASIL, 1991) - destas trabalhadoras, que acabam voltando a trabalhar na mesma função e da mesma forma que trabalhavam quando adoeceram.

Na Empresa 2 nota-se que a forma de organização do trabalho se pauta pela cobrança exagerada e pelo estímulo à competição entre trabalhadores. Esta observação está de acordo com Tomei (2006), que sugere relação entre LER e ansiedade em teleoperadores, que parece estar relacionada à organização do trabalho. Apesar disso, houve relativamente poucos casos graves de transtorno mental relacionado ao trabalho. Uma das possibilidades levantadas é que, neste caso, há pouca expectativa dos trabalhadores em relação ao seu trabalho, que na maioria das vezes é desempenhado por estudantes que têm objetivo de trabalhar em outro ramo e usam o trabalho apenas como forma de custear os estudos; ou donas de casa cujos filhos cresceram e

${ }^{3}$ Distúrbios Psíquicos Menores são distúrbios não psicóticos, como depressão, ansiedade, somatização. 
aproveitam uma parte do dia para melhorar o orçamento familiar ${ }^{4}$. Dessa forma, constituem um grupo de trabalhadores que, pelas características do trabalho e por haver outras possibilidades de inserção social e profissional, têm a possibilidade de se desligar do emprego antes que adoeçam de formas mais graves. Por outro lado, uma parte destes trabalhadores é chefe de família e conta com os adicionais de salário (prêmios por produtividade) para fechar as despesas mensais. Estes são os que mais sofrem pela necessidade de cumprirem metas inatingíveis.

Recentemente, uma onda de suicídios entre teleoperadores preocupou o governo da França. Mais de 20 funcionários da France Telecom suicidaram-se em 2008 e 2009, e alguns deles deixaram cartas afirmando que o suicídio foi motivado pelas difíceis condições de trabalho: cobranças excessivas, "terrorismo" nas supervisões, pressões inaceitáveis para produção e vendas de produtos (SIMONS, 2009). Sugere-se que o que foi descrito no Caso 2 seja considerado evento sentinela (CORRÊA FILHO, 1994).

O caso da Empresa 3 termina em 2004. Poucas pacientes continuaram a ser acompanhadas pelo Cerest, tendo em vista o fato de que, a partir de 2005, foi iniciada descentralização dos atendimentos aos portadores de LER/DORT na rede pública de Campinas. Este processo teve sua primeira etapa concluída em 2007 e coincidiu com o desestímulo gerado pela mudança da empresa para outro estado brasileiro.

O assédio moral ao qual as trabalhadoras da "salinha” foram submetidas ainda não estava, na época, tipificado nas leis brasileiras. O que se pode fazer foi notificar as doenças que resultaram da humilhação e do constrangimento, dar apoio às trabalhadoras por meio de grupos de discussão e interagir com o sindicato da categoria cujos diretores estavam atentos às questões de saúde do trabalhador.

Nas Empresas 4 e 5 se observam quase todos os problemas destacados no início deste relato de experiência, quais sejam, terceirização, precarização ${ }^{5}$, sobrecarga de trabalho, ausência de controle sobre a demanda de trabalho e medo.

As queixas relacionadas à saúde mental e as sugestões de violência psicológica e inclusive de assédio moral têm para os autores deste relato de experiência um sentido particular vindo de merendeiras, porque elas têm um ofício, gostam e se orgulham do que fazem. Servir comida mal preparada, saber que o resultado do seu trabalho não será devidamente apreciado pelos alunos causa nas merendeiras uma dor psíquica maior relacionada ao significado do seu trabalho. São mulheres pobres, na maioria, cuja renda é importante para a economia familiar. Ainda assim algumas delas pedem demissão, mesmo sabendo que terão dificuldade em encontrar outro emprego, na tentativa de ficarem livres do sofrimento causado pelo trabalho cujo sentido percebem como tendo sido degradado. Do ponto de vista da Previdência, a não aceitação das CATs emitidas pelo Cerest ou pelos sindicatos é motivo de grande preocupação. Os médicos peritos do INSS na região do Cerest Campinas sistematicamente recusam CATs que não tenham sido emitidas por empresa, inclusive as emitidas por autoridades sanitárias do Cerest. A concessão de benefícios como auxílio doença acidentário ocorre por força da inserção nas regras do Nexo Técnico Epidemiológico (BRASIL, 2007). A transformação destes benefícios em previdenciários (por doença comum e não do trabalho) acontece sem que haja notificação ou explicação ao segurado.

Verthein (2001), estudando as relações entre médicos peritos do INSS, profissionais da saúde, segurados e sindicatos de trabalhadores, alerta para as relações de poder e construções do saber que legitimam algumas falsas verdades que foram disseminadas por meio de normas e regulamentos caracterizando certa "homogeneidade na recusa" dos médicos peritos (do nexo entre doença e trabalho). O não reconhecimento pelo INSS de doenças comprovadamente relacionadas ao trabalho, como é frequente nas LER/DORT, gera no trabalhador dúvidas quanto à realidade da sua doença, às formas de adoecer e aos riscos do trabalho. Esse contexto propicia o desenvolvimento de sensação de culpa no adoecido e não é incomum encontrarmos trabalhadores que passaram a crer que seu adoecimento teria sido gerado por formas inseguras de trabalhar que ele teria adotado por sua própria falta, assumindo para si a responsabilidade das consequências. Em outros casos, indivíduos duvidavam da própria doença e questionavam a si próprias, se, de fato, não estariam esperando regalias da previdência social às quais não teriam direito.

Se a negativa do INSS ocorre em situações em que o trabalhador sofreu pressões dissimuladas ou assédio moral no trabalho, o fato de sua doença osteomuscular não ter reconhecida origem ocupacional dificulta e, muitas vezes, impede a compreensão do trabalhador acerca do seu processo de adoecimento, acarretando dificuldades na aceitação do tratamento e das limitações que deverá enfrentar no trabalho e nas atividades da vida diária. Dessa forma, os avanços que poderiam ser obtidos através das reflexões nos grupos terapêuticos dão lugar à confusão e a um certo “atordoamento”, que abrem caminho para que o indivíduo tome resoluções que vão contra a sua própria saúde, como, por exemplo, a aceitação de tarefas contraindicadas pela equipe de saúde que participa de seu tratamento. O paciente piora

\footnotetext{
${ }^{4}$ Em 2002 foi aplicado pelo Cerest questionário a todos os trabalhadores da empresa, que incluiu dados demográficos, informações sobre escolaridade, profissões anteriores, expectativas em relação à atividade atual. Os dados colhidos e analisados estão no Cerest Campinas.

${ }^{5}$ A precarização neste caso fica definida pelas condições de trabalho, observadas e descritas anteriormente, de instalações físicas pequenas, mobiliário antigo e malconservado, bancadas de trabalho inadequadas, panelas pesadas, ausência de mecanização do trabalho.
} 
da dor e entra no círculo vicioso perverso descrito no início deste relato.

Supõe-se que, quanto mais o paciente/segurado esteja submetido a este tipo de situação, tanto menor vai se tornando sua capacidade de enfrentamento da situação e recuperação, o que certamente não contribui com a adequada reabilitação profissional e a reinserção no mercado de trabalho.

\section{Conclusões}

Os quatro casos relatados são apenas exemplificativos de demandas que cada vez mais chegam aos Cerests, desafiando as equipes multidisciplinares para o desenvolvimento de novas modalidades de abordagem diagnóstica e terapêutica. Se nas décadas de 80 e 90 do século passado as LER/DORT apresentavam-se como desafio em função da chamada "invisibilidade da doença”, estamos neste momento diante de situações ainda mais difíceis de objetivar. Isto é, situações de trabalho das quais emergem formas diversas de violência psicológica, incluindo o assédio moral e as expressões clínicas de sofrimento mental relacionado ao trabalho que, como vimos nos exemplos acima, muitas vezes surgem como desdobramentos da ocorrência das próprias LER/ DORT. Esta "imaterialidade" não minimiza em nada o drama de quem vive a experiência do adoecimento mental nem a dificuldade dos profissionais de saúde em reconhecê-lo e tratá-lo. Na percepção dos autores, mesmo dentro de uma equipe de saúde do trabalhador experiente, há ainda grande deficiência no reconhecimento das situações em que o trabalho contribui para o adoecimento mental. Seja por essa dificuldade, seja por pragmatismo nos encaminhamentos, os sintomas mentais psíquicos são pouco valorizados nas entrevistas, permanecendo o sofrimento mental subentendido e não adequadamente tratado, tanto no âmbito individual, quanto no coletivo.

No Cerest Campinas temos utilizado a abordagem individual e grupal para os trabalhadores que têm diagnóstico de LER/DORT, dando possibilidade aos trabalhadores para identificar as pressões e a violência psicológica no trabalho, inclusive quando este consubstancia assédio moral, com objetivo de fortalecer o trabalhador e estimulá-lo a fazer valer seus direitos de cidadão.

As atividades em grupo para pacientes com LER/ DORT têm caráter terapêutico e educativo. São feitas nos serviços públicos de saúde por equipes multiprofissionais e têm tido resultados muito bons no que diz respeito ao estímulo à reflexão do processo de adoeci- mento, à discussão sobre as dúvidas e as dificuldades enfrentadas no estabelecimento do diagnóstico e do tratamento. Desta forma, permitem a apropriação da doença pelo trabalhador/paciente, favorecendo o estabelecimento dos limites no trabalho e nas atividades da vida diária e a consciência de cidadão.

Acredita-se que pertencer a estes grupos fortalece, nos trabalhadores, as ideias de participação, equipe, solidariedade, importantes para ajudá-los a suportar as condições de trabalho descritas.

A melhoria das condições objetivas de trabalho, como mobiliário, instrumentos de trabalho, restrição de horas extras, em geral é obtida por meio das ações de fiscalização e ações administrativas feitas pelo Cerest e que não são objeto deste relato. É mais difícil, no entanto, conseguir a mudança de comportamento da empresa que utiliza a pressão por produção, que muitas vezes chega a assediar alguns trabalhadores, por se tratar de situação mais sutil cuja demonstração objetiva do ponto de vista legal e administrativo nem sempre é conseguida (SOBOLL, 2008). No entanto, há notícias alvissareiras quanto à proteção aos trabalhadores; por exemplo, em uma recente decisão de processo judicial sobre dano moral, a juíza relatora conclui que a omissão da empresa, que permitiu que sua empregada trabalhasse em local inadequado e a demitiu quando esta adoeceu, caracteriza má-fé por parte do empregador (BRASIL, 2003). Sugere-se que todos os casos em que o sofrimento mental seja identificado por qualquer profissional de saúde, de serviço público (SUS) ou privado, caracterizando transtorno psíquico em portadores de LER/DORT, sejam notificados. Qualquer membro de equipe de saúde, seja pública ou privada, está habilitado a suspeitar e encaminhar o caso para diagnóstico. A notificação por CAT deverá ser feita na suspeita, cuja investigação resultará em confirmação ou mudança de espécie de benefício. No SUS existe documento específico (BRASIL, 2011) que deverá ser preenchido na confirmação do caso.

Para tanto, é necessário que ocorram sensibilização e capacitação dos profissionais de saúde, em consonância com médicos peritos e equipes de reabilitação profissional do INSS. É urgente que estes profissionais façam o reconhecimento e tomem medidas para o adequado tratamento dos agravos à saúde mental em trabalhadores com diagnóstico de LER/DORT. Isto inclui a necessidade de que esta dimensão também seja considerada na decisão quanto ao momento de retorno ao trabalho e na indicação e programação da reabilitação profissional.

\section{Contribuições de autoria}

Salerno, V.: contribuiu substancialmente no projeto e no delineamento, no levantamento de dados e em sua análise e interpretação. Silvestre, M.: colaborou na elaboração e na revisão crítica do manuscrito. Sabino, M.: colaborou na elaboração e na revisão crítica do manuscrito e na aprovação final da versão publicada. 


\section{Referências}

ALVES, M. G. M. et al. Estresse no trabalho e hipertensão arterial em mulheres no estudo pró-saúde. Revista de Saúde Pública, São Paulo, v. 43, n. 5, p. 893896, 2009.

BRANT, L. C.; DIAS, E. C. Trabalho e sofrimento em gestores de uma empresa pública em reetruturação. Cadernos de Saúde Pública, Rio de Janeiro, v. 20, n. 4, p. 942-949, jul.-ago. 2004.

BRASIL. Ministério da Previdência Social. Decreto $\mathrm{n}^{\mathrm{o}} 6.042$ de 12 de fevereiro de 2007. Altera o Regulamento da Previdência Social, aprovado pelo Decreto $\mathrm{n}^{\mathrm{o}}$ 3.048, de 6 de maio de 1999, disciplina a aplicação, acompanhamento e avaliação do Fator Acidentário de Prevenção - FAP e do Nexo Técnico Epidemiológico, e dá outras providências. Diário Oficial [da] República Federativa do Brasil, Poder Executivo, Brasília, DF, 12 fev. 2007.

. Ministério da Previdência Social. Lei Federal $\overline{\mathrm{n}^{\mathrm{o}}}$ 8.213, de 24 de julho de 1991. Dispõe sobre os Planos de Benefícios da Previdência Social e dá outras providências. Diário Oficial [da] República Federativa do Brasil, Poder Executivo, Brasília, DF, 14 ago. 1991.

. Ministério da Saúde. Portaria GM/MS no 2.472, de 31 de agosto de 2010. Atualiza a relação de doenças, agravos e eventos de notificação compulsória, define as terminologias adotadas em legislação nacional, conforme disposto no Regulamento Sanitário Internacional 2005 (RSI 2005), a relação de doenças, agravos e eventos em saúde pública de notificação compulsória em todo o território nacional e estabelecer fluxo, critérios, responsabilidades e atribuições aos profissionais e serviços de saúde. Brasília: Ministério da Saúde, 2010. Disponível em: <http://www.saude.rn.gov.br/content/ aplicacao/sesap_cerest/legislacao/gerados/portaria\%20 no\%202472.pdf $>$. Acesso em: 3 maio 2011.

. Ministério da Saúde. Portaria GM/MS no 104, de 25 de janeiro de 2011. Define as terminologias adotadas em legislação nacional, conforme o disposto no Regulamento Sanitário Internacional 2005 (RSI 2005), a relação de doenças, agravos e eventos em saúde pública de notificação compulsória em todo o território nacional e estabelece fluxo, critérios, responsabilidades e atribuições aos profissionais e serviços de saúde. Brasília: Ministério da Saúde, 2011. Disponível em: <http://portal.saude.gov.br/portal/arquivos/pdf/ portaria_104_26_2011_dnc.pdf $>$. Acesso em: 28 maio 2011.

Poder Judiciário. Tribunal Regional do Trabalho da 15ํ Região. Quarta Câmara (Segunda Turma). Acórdão do julgamento do Recurso Ordinário do Processo 0151800-79.1997.5.15.0053 RO publicado em 05/09/2003. Disponível em: <http:// consulta.trt15.jus.br/consulta/owa/pDecisao.wAcor dao?pTipoConsulta $=$ PROCESSO\&n_idv $=493444>$. Acesso em: 28 abr. 2011.
BROUSSE, G. et al. Psychopathological features of a patient population of targets of workplace bullying. Occupational Medicine, Oxford, v. 58, n. 2, p. 122-128, 2008.

CARLOTTO, M. S.; PALAZZO, L. S. Síndrome de burnout e fatores associados: um estudo epidemiológico com professores. Cadernos de Saúde Pública, Rio de Janeiro, v. 22, n. 5, p. 1017-1026, 2006.

CORRÊA FILHO, H. R. Outra contribuição da epidemiologia. In: BUSCHINELLI, J. T. P.; ROCHA, L. E.; RIGOTTO, R. M. (Org.) Isto é trabalho de gente? Vida, doença e trabalho no Brasil. Petrópolis: Vozes, 1994. Cap. 12, p. 187-214.

FERNANDES, E. Cozinheiras do Programa de alimentação escolar fazem curso. Prefeitura Municipal de Campinas. Notícias, 26 jan. 2010. Disponível em: <http://www.campinas.sp.gov.br/noticias-integra. php?id=503>. Acesso em: 18 fev. 2010.

FERREIRA JR., M. Relação dos fatores de risco ligados ao trabalho interativo usando computador e telefone com a etiopatogenia dos distúrbios osteomusculares de região cervical, ombros e membros superiores. 1997. 109 f. Tese (Doutorado em Patologia)-Faculdade de Medicina da Universidade de São Paulo, São Paulo, 1997.

GLINA, D. M. R. et al. Saúde mental e trabalho: uma reflexão sobre o nexo com o trabalho e o diagnóstico, com base na Prática. Cadernos de Saúde Pública, Rio de Janeiro, v. 17, n. 3, p. 607-16, maio/jun., 2001.

KARASEK, R. Job Content Questionnaire user's guide. Lowell: University of Massachusetts, 1985.

KUORINKA, I.; FORCIER, L. (Ed.) Work-related musculoskeletal disorders (WMSDs): a reference book for prevention. Great Bretain: Taylor \& Francis, 1995.

LEYMANN, H. Mobbing and psychological terror at workplaces. Violence and Victims, v. 5, n. 2, p. 119126, 1990.

MACEDO, L. E. T. et al. Estresse no trabalho e interrupção de atividades habituais, por problemas de saúde, no Estudo Pró-Saúde. Cadernos de Saúde Pública, Rio de Janeiro, v. 23, n. 10, p. 2327-2336, 2007.

MAGNAVITA, N. Strain, disturbi d'ansia, depressione e disturbi muscoloscheletrici nelle attività di assistenza sociale. Giornale Italiano di Medicina Del Lavoro ed Ergonomia, Roma, v. 31, n. 1, p. 24-29, 2009.

MINAYO, M. C. S. 3. ed. O desafio do conhecimento: pesquisa qualitativa em saúde. São Paulo: Hucitec; Abrasco, 1994.

ORGANIZAÇÃO MUNDIAL DA SAÚDE. CIF Classificação Internacional de Funcionalidade, Incapacidade e Saúde. Centro colaborador da Organização Mundial da Saúde para a família de 
classificações internacionais. Coordenação da tradução: Cássia Maria Buchalla. São Paulo: Edusp, 2003.

PALACIOS, M.; DUARTE, F; CÂMARA, V. M. Trabalho e sofrimento psíquico de caixas de agências bancárias na cidade do Rio de Janeiro. Cadernos de Saúde Pública, Rio de Janeiro, v. 18, n. 3, p. 843-851, 2002.

REIS, E. J. F. B. et al. Trabalho e distúrbios psíquicos em professores da rede municipal de Vitória da Conquista, Bahia, Brasil. Cadernos de Saúde Pública, Rio de Janeiro, v. 21, n. 5, p. 1480-1490, 2005.

RIGOTTO, R. M. Investigando a relação saúde e trabalho. In: BUSCHINELLI, J. T.; ROCHA, L. E.; RIGOTTO, R. M. Isto é trabalho de gente? Petrópolis: Vozes, 1994. p. 159-177.

ROCKWELL, E. Etnografia e a teoria da pesquisa educacional. In: EZPELETA, J.; ROCKWELL, E. Pesquisa participante. São Paulo: Cortez, 1986. p. 31-54.

ROMEO, L. et al. Follow up of person-related bullying and work-related bullying: evaluation of effectiveness of interventions. Giornale Italiano di Medicina del Lavoro ed Ergonomia, Italy, v. 29, n. 3, suppl., p. 696698, jul./set. 2007.

SALERNO, V. L. Considerações sobre a terceirização e as possíveis implicações nos riscos de acidentes de trabalho fatais. 1998. 95 f. Dissertação (Mestrado em Saúde Pública)-Faculdade de Saúde Pública, Universidade de São Paulo, São Paulo, 1998.

SÃO PAULO (Estado). Governo Estadual. Lei Estadual $n^{\circ}$ 10.083, de 23 de setembro de 1998. Dispõe sobre o Código Sanitário do Estado. Diário Oficial do Estado de São Paulo, São Paulo, SP, 24 set. 1998, Seção I.

. Governo Estadual. Secretaria de Estado do Governo e Gestão Estratégica. Decreto nº 47.297, de 6 de novembro de 2002. Dispõe sobre o pregão, a que se refere a Lei federal $\mathrm{n}^{\circ} 10.520$, de 17 de julho de 2002, e dá providências correlatas. Diário Oficial do Estado de São Paulo, São Paulo, SP, 7 nov. 2002. v. 112, n. 213. Disponível em: <http://www. al.sp.gov.br/repositorio/legislacao/decreto/2002/ decreton.47.297,\%20de\%2006.11.2002.htm > . Acesso em: 26 abr. 2011.
SATO, L.; BERNARDO, M. H. Saúde mental e trabalho: os problemas que persistem. Ciência e Saúde Coletiva, Rio de Janeiro, v. 10, n. 4, p. 869-878, 2005.

SCOPEL, M. J. Retorno ao trabalho: trajetória e trabalhadores metalúrgicos portadores de LER/DORT. 2005. 130 f. Dissertação (Mestrado em Psicologia Social e Institucional)-Faculdade de Psicologia, Universidade Federal do Rio Grande do Sul, Rio Grande do Sul, 2005.

SILVA, A. M. Condições de trabalho e adoecimento dos trabalhadores em teleatendimento: uma breve revisão. InterfacEHS, São Paulo, v. 1, n. 3, artigo 7, abr. 2007.

Disponível em: < http://www.interfacehs.sp.senac.br > Acesso em: 10 abr. 2009.

SIMONS, S. Governo francês interfere para conter onda de suicídios na France Telecom. Spiegel On-Line International, 17 de setembro de 2009. Disponível em: < http://www.spiegel.de/international/ world/0,1518,649715,00.html>. Acesso em: $17 \mathrm{fev}$. 2010.

SOBOLL, L. A. P. Assédio moral-organizacional: uma análise da organização do trabalho. São Paulo: Casa do Psicólogo, 2008.

SUWAZONO, Y. et al. Benchmark dose of working hours in relation to subjective fatigue symptoms in Japanese male workers. Annals of Epidemiology, v. 16, n. 9, p. 726-732, 2006.

TOMEI, G. et al. Anxiety, musculoskeletal and visual disorders in video display terminal workers. Minerva Medica, Italy, v. 97, n. 6, p. 459-466, 2006.

VERTHEIN, M. A. R. Jogos de poder instituindo saber sobre as Lesões por Esforços Repetitivos: as redes discursivas da recusa do nexo. 2001. $164 \mathrm{f}$. Tese (Doutorado em Saúde Pública)-Centro de Estudos da Saúde do Trabalhador e Ecologia Humana, Escola Nacional de Saúde Pública, Fiocruz, Rio de Janeiro, 2001.

WANG, J. L. et al. The relationship between work stress and mental disorders in men and women: findings from a population - based study. Journal of Epidemiology and Community Health, Canada, v. 62, n. 1, p. 42-47, 2008. 